\title{
Discurso imagético e representação do iraque nas capas da revista veja
}

\section{Imaging speach and iraq's representation on cover of veja magazine}

\author{
Marcia Boroski ${ }^{1}$
}

\begin{abstract}
Resumo
O estereótipo do mundo islâmico é, frequentemente, difundido, através dos meios de comunicação, por meio dos signos do caos, do terror, da inferioridade e do mal. Estes signos fazem parte de um conceito chamado orientalismo, que foi proposto pelo historiador Edward Said (2007). A partir da compreensão desse conceito, como uma visão cultural do ocidente sobre o oriente, o objetivo deste trabalho é entender como se dá a representação destes signos na imprensa brasileira, especificamente, no caso da representação do Iraque na cobertura da Guerra do Golfo, em 1991, e da invasão Norte-americana, em 2003, pela revista Veja. A pesquisa identificou este discurso, por meio dos signos ideológicos, a partir dos eixos de produção de sentido de Harry Pross (1980) e do conceito de ideologia, discutido por Terry Eagleton (1997), de base marxista. Viu-se que, em ambos os casos, o posicionamento da revista deu-se a partir de uma visão orientalista. Entretanto, em 1991, o inimigo a ser derrotado foi figurado por Saddam Hussein; já em 2003, o oponente era a nação iraniana, como um todo.
\end{abstract}

Palavras-chaves: Orientalismo. Iraque. Guerra. Ideologia. Signos.

\begin{abstract}
The stereotypes of the islamic word are frequently disseminated by through the media, through the signs of the chaos, terror, inferiority and evil. These signs are part of a concept called orientalism, proposed by a historian Edward Said (2007). By understanding of this concept, as a cultural vision of the West over the East, the aim of this work is to understand how is the representation of these signs in the Brazilian press, specifically, in the case of representation Iraq's coverage of the Gulf War in 1991 and the North American invasion in 2003 by the magazine Veja. The research identified this discourse through ideological signs, from the axes of meaning production of Harry Pross (1980) and the concept of ideology discussed by Terry Eagleton (1997), a marxist basis. It was seen that in both cases, the positioning of the magazine is made from a orientalist vision. However, in 1991 and the enemy to be defeated was figured by Saddam Hussein; already in 2003, the opponent was the Iranian nation as a whole.
\end{abstract}

Keywords: Orientalism. Iraq. War. Ideology. Signs.

${ }^{1}$ Graduada em Comunicação Social - Jornalismo pela Universidade Estadual de Londrina. Mestranda no programa de PósGraduação em Comunicação pela mesma instituição. Bolsista CAPES. E-mail: marciaboroski@yahoo.com.br. 


\section{Introdução}

O fotojornalismo é composto por signos, linguagens, culturas, ideologias, mitos, contextos e convenções. Barthes (1990) diz que a fotografia tem uma mensagem fotográfica própria e é composta por uma parte denotativa e outra conotativa. A parte denotativa está ligada ao conceito de fotografia como espelho do real. Já a conotativa é a que suporta os signos, as linguagens, as culturas e as ideologias que compõem uma fotografia.

Apartir destas premissas, o objetivo deste trabalho é verificar como se deu a representação de Saddam Hussein e do Iraque, nas capas da Veja, publicadas no período da Guerra do Golfo, no ano de 1991, e da invasão Norte-americana, em 2003. Totalizando os dois acontecimentos, a revista veiculou 14 edições, cujas capas continham tais temáticas. Entretanto, o corpus deste presente trabalho é composto por quatro capas que concentram uma série de signos discutidos ao longo do texto. Nelas, será possível encontrar irregularidades e regularidades que servirão de base para os aspectos conclusivos do trabalho. Deve-se ter em vista, também, que este artigo é fruto de um projeto maior, em que todo o material veiculado pela Veja foi analisado. A análise dos dois períodos distintos permitirá traçar relações e pontos em comum nas coberturas jornalísticas dos dois conflitos. Apesar de alguns livros trazerem a invasão Norte-americana denominada como Segunda Guerra do Golfo, este trabalho utilizará o termo "Invasão" apenas para não causar confusão de sentido ao leitor, já que o termo Segunda Guerra do Golfo não é tão difundido. Outro ponto é o sentido ideológico que "Norte-americana" pode tomar. Por isso, na tentativa de se manter objetiva, a pesquisa utilizou o termo "Norte-americana", entendendo que ele se refere aos Estados Unidos.

Além disso, também, serão descritos quais signos são utilizados para representar o conflito e sob quais circunstâncias eles aparecem. Para isso, utilizaremos os conceitos de orientalismo do historiador Edward Said (2007), no qual, o oriente é representado pelo ocidente, sob os signos do caos, do terror, da inferioridade e da ausência de autogestão, ou seja, o orientalismo é uma visão cultural do ocidente sobre o oriente.

O estudo desses signos visará identificar um padrão de representação do mundo oriental pela revista Veja. A intenção deste trabalho não é apenas discutir e estudar as coberturas que compõem o recorte. Antes disso, é importante entender que, por meio de determinados episódio, é possível traçar uma conduta e um alinhamento político e ideológico de um veículo de imprensa.

\section{Imagem e Ideologia}

Neste trabalho, discutiremos a questão da experiência da relação social, ou seja, da experiência com o outro, por meio das relações que a mídia estabelece entre os indivíduos. Compreendendo que a mídia contemporânea é baseada em imagens (fotografia, vídeo, ilustrações, etc), as relações que serão discutidas neste trabalho têm a ver com a percepção do mundo e de si mesmo, através das imagens midiáticas. Por isso, o estudo da alteridade no plano ideológico se faz pertinente. Tal experiência se dá com a presença de códigos, como, por exemplo, o discurso imagético, o qual é conduzido por meio, ou contendo, traços de ideologia.

O conceito de ideologia - de base marxista - seria o da falsa consciência da realidade, a partir de ferramentas como o trabalho, no qual, o indivíduo não consegue enxergar o sistema por inteiro. Ao indivíduo, a divisão social do trabalho é afirmada como algo que sempre esteve ali e daquele jeito, impassível de mudança e condizente com a capacidade do indivíduo. Então, a divisão do trabalho, ou sociedade privada - que para Marx são sinônimos - seria não só berço da ideologia, mas, também, o motor e combustível de permanência do sistema.

Ao fazer referência à ideologia como um conceito ligado ao poder, John B. Thompson (apud 
EAGLETON, 1997, p. 19) diz que o objetivo da ideologia "é estudar os modos pelos quais o significado (ou a significação) contribui para manter as relações de dominação". Segundo Eagleton (1997), ideologia tem mais a ver com discurso que com linguagem. Desta forma, o efeito discursivo provém de quem está falando o quê, com quem e com que finalidade.

Descrever ideologia como um discurso "interessado", portanto, requer a mesma qualificação que caracterizála como uma questão de poder. Em ambos os casos, o termo só é eficaz e elucidativo se nos ajuda a distinguir entre aqueles interesses e conflitos de poder que, em qualquer época, são claramente centrais a toda uma ordem social e aqueles que não são (EAGLETON, 1997, p. 23)

No livro Questão da Ideologia, Leandro Konder (2002) traz conceitos de diversos autores acerca do tema. Por exemplo, os conceitos de Mikhail Bakhtin são utilizados para análises de objetos culturais, em geral. Isso justifica a presença dos conceitos do autor de forma tão particular. Sobre a carnavalização, conceito de Bakhtin, Konder (2002, p. 113) diz que o "clima de euforia, de embriaguez utópica, tem sido sempre encarado com apreensão pelos detentores do poder e zeladores da ordem". A questão da carnavalização, então, é entendida como um suporte para a ideologia. A existência da ideologia está diretamente vinculada ao signo. O signo, que pode ser carregado de significados, é um dos meios que a ideologia utiliza para se propagar. O cotidiano social é capaz de consolidar os sistemas ideológicos.

"Odomínio do ideológico coincide como domínio dos signos: são mutuamente correspondentes. [...] $\mathrm{O}$ edifício social dos signos ideológicos existe em constante mudança e a questão da ideologia, para Bakhtin, consiste em saber como o signo reflete e refrata a realidade em transformação." (KONDER, 2002, p. 115).

Konder (2002), também, explica que, necessariamente, a ligação entre linguagem e ideologia requer um observador, o qual será o agente que constatará a presença de ideologia na estrutura e no funcionamento da linguagem. Entretanto, a linguagem não permanece imune à ideologia, ela se vê obrigada a lutar pelo "valor intrinsecamente qualitativo - e incomensurável - que lhe é inerente: a busca permanente da expressão da dimensão constituinte da práxis humana (e não apenas da expressão do saber constituído).” (KONDER, 2002, p. 157).

A linguagem, ao receber pressões ideológicas, sofre distorções, e isso, segundo Konder (2002), era um aspecto considerado por Bakhtin. A fim de evitar a coisificação da linguagem, os seres reagiam. As forças para tal ação estariam presentes na própria fala das camadas populares. Entretanto, segundo Konder (2002, p.163), "a questão da ideologia não pode ser efetivamente resolvida no âmbito exclusivo da linguagem".

\section{Orientalismo}

A linguagem ou o discurso são recursos que podem ser utilizados para propagar determinada ideologia. O orientalismo, conceito proposto pelo historiador Edward W. Said (2007), funciona como tipo de discurso ideológico que o ocidente tem sobre o oriente. Said (2007) compreende que o discurso orientalista é preconceituoso e destaca que "a televisão, os filmes e todos os recursos da mídia forçaram a informação para dentro de moldes cada vez mais padronizados”. (SAID, 2007, p. 38). Desta forma, o conceito apresentado por Said (2007) aproxima-se de um discurso hegemônico, quando se predomina na fala das sociedades ocidentais e de suas instituições.

Segundo Said (2007), o orientalismo configurase como uma forma de exercício discursivo de poder do ocidente sobre o oriente que se consolidou ao longo da história, tanto na literatura quanto na academia e, mais recentemente, nos meios de comunicação de massa. 
Não se deve supor que a estrutura do orientalismo não passa de uma estrutura de mentiras ou de mitos que simplesmente se dissipariam ao vento, se a verdade a seu respeito fosse contada. Eu mesmo acredito que o orientalismo é mais particularmente valioso como um sinal do poder europeu-atlântico sobre o oriente do que como um discurso verídico sobre o oriente. [...] O orientalismo, portanto, não é uma visionária fantasia europeia sobre o oriente, mas um corpo elaborado de teoria e prática em que, por muitas gerações, tem se feito considerável investimento material (SAID, 2007, p. 33).

O orientalismo afasta a identificação do homem com o outro, já que o ser ocidental identifica o oriental pelas lentes do orientalismo. Muito além de eixos de dominação, o discurso permeia linhas culturais e já se naturalizou. A desconstrução e identificação dos elementos deste discurso e o estabelecimento de um crivo racional permitirão tentar alcançar uma análise livre de tendências estereotipadas.

\section{História}

Para situar historicamente a relevância dos eventos cujas coberturas jornalísticas foram escolhidas para serem analisadas neste trabalho, faz-se necessário contextualizar acerca das histórias dos conflitos. A primeira Guerra do Golfo começou em agosto de 1990, quando o exército iraquiano invadiu o Kuwait. O conflito envolveu, também, outros países que se aliaram e se posicionaram contra o Iraque. Ao todo, eles somavam mais de 20 países e eram liderados por Estados Unidos e GrãBretanha.

O objetivo do Iraque, ao invadir o Kuwait, era o de anexar o país ao seu território, com o intuito de controlar a produção de petróleo kuwaitiana. Além disso, Saddam Hussein buscava novos acessos ao golfo Pérsico e projeção no cenário árabe. Como forma de pressionar a saída do Iraque do Kuwait, o país sofreu embargos comerciais internacionais. A força bélica utilizada nessa guerra foi a maior desde a Segunda Guerra Mundial, o território iraquiano sofreu diversos e intensos bombardeios. Em 28 de fevereiro de 1991, o Iraque anunciou a devolução do Kuwait, pela rádio de Bagdá. O fim da guerra não cessou a crise no país, o qual continuou sendo alvo de acusações a respeito da produção e armazenamento de armas nucleares, biológicas, químicas e de mísseis de longo alcance.

Já o segundo conflito foi fruto das diversas tensões entre os EUA e o Iraque, desde o 11 de setembro. Além disso, outro motivo para o conflito era a alegação de que o presidente Saddam Hussein mantinha um arsenal de armas químicas que ameaçava a paz mundial. Mesmo não comprovando a existência do arsenal bélico iraquiano, o governo norte-americano invadiu o Iraque e conseguiu promover o julgamento e a posterior condenação do ditador Saddam Hussein. A ocupação norteamericana é contestada, por nunca provarem a existência das polêmicas máquinas de exterminação ou armas de destruição em massa e pela guerra não ter um final definitivo. Outro ponto que se levanta em discordância é interesse no controle do petróleo iraquiano.

\section{Metodologia}

Para identificar e compreender os signos do orientalismo, para a concepção de um discurso imagético da representação do Iraque, utilizamos, como metodologia, os eixos de produção de sentido de Harry Pross (1980). O processo de imersão nas imagens nos remete às experiências pré-predicativas. Conforme o pensador alemão, estas experiências se realizam na primeira infância e se revelam duradouras. Ao olhar uma imagem, o receptor faz isso superficialmente, no primeiro momento, e, após o contato inicial, é que resgata informações, lembranças e até outras imagens interiorizadas anteriormente, que servirão de respaldo para a construção de sentido posterior daquilo que vê.

A partir das experiências pré-predicativas do ser humano, formam-se eixos de produção de sentido. Estes eixos são os responsáveis por atribuir significado às imagens percebidas pelo receptor e podem encaminhar o leitor àquilo que o produtor das imagens deseja que ele perceba. 
Segundo Pross (1980), os eixos de produção de sentido podem ser considerados binários, pois possuem uma oposição básica. Os eixos trabalhados por Pross (1980) são: acima-abaixo; dentro-fora e claro-escuro. $\mathrm{O}$ autor afirma que eles são polarizados, ou seja, há sempre um polo negativo em oposição a um polo positivo e um dos polos sempre se sobressai ao outro, sendo, então, assimétricos. Pross (1980) evidencia, ainda, que são os eixos de produção de sentido que permitem que o ser humano se comunique.

As fotografias, com estes aportes sígnicos, pretendem carregar o olhar do leitor para dentro e, com isso, conseguir colocá-lo no mundo das representações. Desta forma, no campo das imagens técnicas, superfícies informadas ganham significados diferentes. A foto sozinha tem um sentido. Quando inserida na capa, com discursos verbais como a manchete e o próprio "enquadramento", adquire nova significação.

Como já foi dito, as binariedades são polarizadas, ou seja, cada polo recebe um valor positivo ou negativo. Quando um dos polos se sobressai ao outro, dizemos que há uma assimetria entre eles. Porém, o polo negativo é sempre percebido ou sentido mais fortemente.

É isso que acontece nas imagens das capas que este trabalho propõe analisar. Em sua maioria, a combinação binária se faz presente e a oposição bem e o mal prevalece. O polo negativo é percebido com mais intensidade nas capas, uma vez que a distribuição dos elementos na página contribui para que ocorra a determinação do olhar do leitor diante das imagens.

Esse condicionamento é o que Harry Pross (1980) chama de experiências pré-predicativas. O olhar do homem já tem pré-determinado qual movimento irá fazer, deliberado pelos elementos e pela forma como os elementos visuais são apresentados. Quase que inconscientemente, o homem percorre determinados trajetos. Os eixos e produção de sentidos seriam, então, orientações que o olhar vai seguir no percurso de leitura das imagens.
Estes eixos de produção de sentido formam, ou conformam a eles, todos os conceitos e ideais que o homem irá atribuir às imagens (e, também, a outros textos culturais) naquele momento inicial de pré-visualização. [...] dão validade para os demais símbolos, inclusive os construídos pelas imagens (MENEGHETTI, 2010, p. 83).

\section{Análise}

Pode-se afirmar que a análise comparativa dos dois conflitos mostrou alguns pontos em comum e outros divergentes. Em geral, no primeiro conflito - Guerra do Golfo, 1991 - a figura de Saddam teve mais espaço na revista. Naquele momento, ele apareceu como um inimigo a ser derrotado. Entretanto, em 2003 - invasão Norte-americana o inimigo a ser combatido era a nação iraquiana, como um todo. Essa batalha era justificada, através da luta contra o terror, o caos, o mal e a ditadura iraquiana, elementos que constituem, em parte, os signos ideológicos do orientalismo.

Conforme já foi dito, a ideologia, para tornarse falsa consciência da realidade, passa por diversas etapas até alcançar a completa validação. Uma vez validada, é necessário ainda buscar uma permanência, o que, também, requer determinados "artifícios". Uma das formas de validar uma ideologia é a repetição de uma informação. No caso da revista Veja - nos dois conflitos no Iraque, quando divulgou imagens das figuras representativas do Iraque, de Saddam e da chamada coalizão - a cobertura se deu seguindo padrões de representação que podem ser confirmados pelos eixos de produção de sentido, os quais interferem na forma como lemos os elementos da capa.

Apesar de certos elementos indicarem um padrão de representação, o tratamento da revista se diferenciou, em alguns aspectos, nos dois conflitos. No primeiro, em 1991, a figura de Saddam Hussein apareceu personificando o inimigo. O ditador aparecia como um mal a ser derrotado. Já no segundo conflito, a figura de Saddam não se sobressaiu, o alvo era o Iraque enquanto nação. O discurso, nesse 
segundo momento, era da necessidade de combate a uma nação, cujo potencial argumentativo estava na possível presença de armas químicas no Iraque e no julgamento de que naquela região o mal estava instaurado e era preciso levar a paz.

$\mathrm{Na}$ Guerra do Golfo, em 1991, a figura de Saddam apareceu representada sob os signos da tirania, daquela imagem que provoca a guerra sangrenta, que atua como um jogador e que, no final, "foi moído" (Figura 1). Esta caracterização articula o imaginário de forma a considerar a figura de Saddam apenas sob estas perspectivas. Como foi dito anteriormente, a apesar de conseguirmos nos soltar da imersividade das imagens, a experiência na qual a compreendemos e interpretamos está fadada a se orientar por signos culturais e ideológicos. Dada a circunstância e o conceito de orientalismo de Edward Said (2007), a imagem de Saddam Hussein, representada por estes signos, só vinha a somar com o imaginário que envolve a cultura ocidental, em que o líder iraquiano é o ícone que leva o caos, incentiva e subsidia o terrorismo, promove a maldade e ostenta riquezas - recorda-se aqui o motivo que levou Saddam Hussein a invadir o Kuwait, o controle do petróleo no Oriente Médio.

Figura 1 - Signos do orientalismo 1.
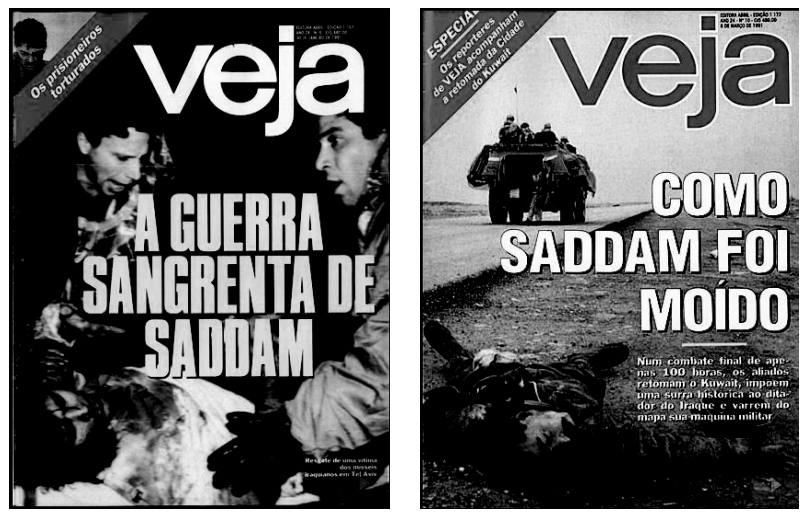

Fonte: Veja (1991).

Durante a cobertura da invasão Norte-americana contra o Iraque, George W. Bush travou uma "disputa contra o mal". A capa do dia 23 de março de 2003 (Figura 2) foi composta por uma imagem do primeiro bombardeio a Bagdá. A capital bombardeada foi representada pela palavra apocalipse, que era a manchete. Já o exército iraquiano, como manchete na revista Veja no dia 4 de abril de 2003 (Figura 2), foi representado pelo signo de um único soldado, um homem, cuja denominação era a face da derrota. Os elementos apresentados pela revista - o caos na manchete do bombardeio e o soldado ícone da derrota - caracterizam coisas negativas que precisam ser tratadas por alguém munido de poder e habilidade. Estes elementos tornam-se signos ideológicos, usados para validar a presença dos EUA no Iraque, que não havia recebido aprovação mundial. Nessa circunstância, pode-se dizer que a revista alinhou-se ao discurso dos EUA, ao mostrar os ícones da guerra no Iraque - a capital e o exército, por exemplo - por meio de signos ideológicos.

Figura 2 - Signos do orientalismo 2
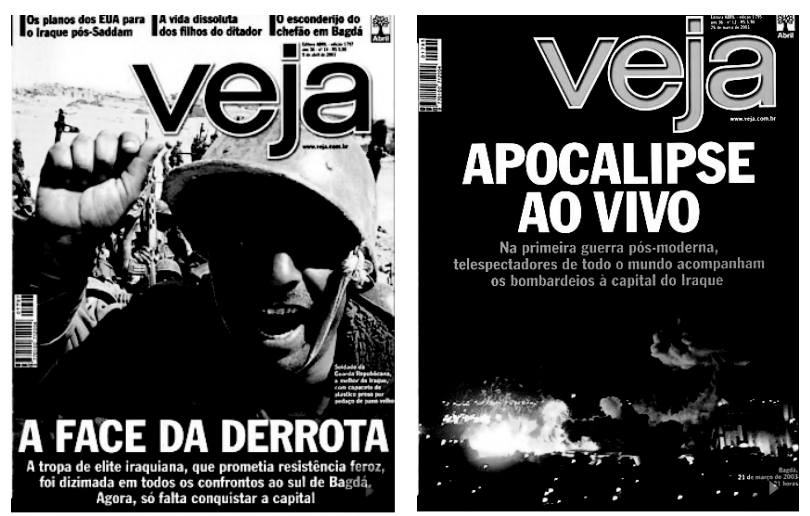

Fonte: Veja (2003).

\section{Considerações Finais}

Pode-se afirmar que a análise comparativa dos dois conflitos mostrou alguns pontos em comum e outros divergentes. Em geral, no primeiro conflito - Guerra do Golfo, 1991 - a figura de Saddam teve mais espaço. Naquele momento, ele apareceu como um inimigo a ser derrotado. Entretanto, em 2003 
invasão Norte-americana - o inimigo a ser combatido era a nação iraquiana, como um todo. Essa batalha era justificada pela luta contra o terror, o caos, o mal e a ditadura iraquiana, elementos que constituem, em parte, os signos ideológicos do orientalismo.

No conflito de 1991, pode-se dizer que a mídia focou na figura de Saddam, já que o motivo da guerra - a invasão do Kuwait - era uma decisão dele. Em 2003, a coalizão não contou com o apoio da ONU, nem do mundo, por isso, havia a necessidade de justificar tal invasão. $O$ uso de signos ideológicos do orientalismo, como forma de validar a presença norte-americana no Iraque, não só reforçou o estereótipo hegemônico, já presente na cultura ocidental, mas, também, ajudou a validar a presença da força bélica norte-americana no Iraque. As imagens imersivas das capas carregam o olhar do leitor para dentro desse imaginário. Esta experiência regula o olhar a se orientar pelos signos ideológicos e culturais apresentados, ou seja, pelos signos do orientalismo.

Ainda sobre cobertura da guerra de 2003, outros fatores que contribuíram para a construção e validação de um discurso imagético ideológico foram as capas como a de 23 de março de 2003, onde a capital Bagdá aparece bombardeada e representada pela manchete: Apocalipse (Figura 2). Esse discurso mexe com um imaginário de elementos de monstruosos que inspiram o terror. Tais elementos caracterizam coisas ruins que precisam ser tratadas por alguém munido de poder e habilidade, no caso, personificado na figura dos EUA, e tornam-se signos ideológicos utilizados, também, para validar a presença dos EUA no Iraque.

Durante a Guerra do Golfo, quando o inimigo a ser combatido era o personagem de Saddam, as manchetes apontavam que aquela guerra pertencia a Saddam Hussein. Na figura 1, verifica-se leve contraplongé, aprisionando o olhar do leitor. Com o olhar captado, os principais signos ideológicos estão no discurso verbal, com o jogo das palavras: sangrenta e moído.
Com relação ao eixo dentro-fora, avalia-se que a Figura 2, na capa ocupada pelo soldado iraquiano, cuja face é a da "derrota" (termo generalista utilizado na manchete), entende-se que a vestimenta precária (como o capacete que parece ser de plástico), juntamente com a manchete e o conceito de orientalismo, articulam um discurso de uma guerra já vencida. O movimento quase ilusório do soldado caminhando para fora da capa, em direção ao leitor, promove determinadas produções de sentido, como, por exemplo, certa sensação de que aqueles elementos visuais se aproximam. No caso, de que a derrota se aproxima.

O eixo claro-escuro foi identificado, também, na capa que mostra o bombardeio que iniciou a invasão, em 2003. O eixo claro-escuro é entendido por meio de uma assimetria simplista: escuro remete ao mal e claro ao bem. Partindo disso, é possível compreender um tipo de representação que joga com o imaginário, ao colocar como único ponto de luz o armamento de guerra ou ainda as explosões. Como se não houvesse saída para a paz, senão pela Guerra.

Entendendo ambas as guerras como encenações com dois tipos de atores, a análise do eixo acimaabaixo evidencia que aquele ator que representa o iraquiano aparece na Figura 1, na capa cuja manchete é "Como Saddam foi moído", localizado na parte inferior, no "abaixo", o qual possuiu conotações negativas, já que a produção de sentido nos eixos se dá a partir desta assimetria. E na capa cuja manchete é "Guerra sangrenta de Saddam", na qual o indivíduo ferido pela guerra está na parte inferior, enquanto a representação do socorro está na parte superior.

É necessário entender que os meios de comunicação interferem de diversas maneiras nos processos de argumentação e decisão da sociedade. Conforme Rousiley Maia (2008), os profissionais da mídia regulam as leis de produção de sentido e a forma como esse material será apresentado para o público. O formato engloba produtos jornalísticos, 
de entretenimento e publicitários. Essa relação com sociedade é assimétrica, e alguns atores, ou algumas ideias, recebem mais espaço que outras, por exemplo. Além disso, a questão da visibilidade dada a esses atores é condição para o reflexo daquilo que ele representa e interfere na sociedade.

Os conceitos trazidos por esta autora subsidiam e suscitam novas questões acerca dos resultados desta pesquisa. Dada a influência da mídia nos debates realizados na sociedade, pode-se entender que o modo como ela realiza seus produtos culturais e como eles produzem sentido, visualmente falando, são ações que necessitam serem avaliadas, para compreender como se dá receptividade destes produtos ou ainda, em maior escala, a averiguação de episódios os quais a mídia não se mostrou responsável com sua função social

Como foi visto, os resultados mostram que foram captados padrões de representação da figura do Iraque e de Saddam, nos episódios dos dois conflitos. Esse comportamento pontual pode revelar uma conduta pautada na apresentação dessas figuras, exclusivamente, sob os signos do orientalismo. A cobertura da Guerra do Golfo foi espetacularizada pela mídia, em geral, e isso contribuiu para a formação de determinados estereótipos. Essa guerra aconteceu sob os holofotes e a construção da história, também, é, constantemente.

A apresentação do mundo árabe, sobretudo do Iraque e de Saddam Hussein, objetos deste trabalho, exclusivamente sobre os signos do orientalismo, desconsiderando outros aspectos políticos, culturais e até humanos, é uma conduta que suscita a discussão de como se pode apresentar no jornalismo brasileiro, ou até no ocidental, esse povo, sem que seja por meio destes signos. Mesmo que esta pesquisa tenha apontado que os signos ideológicos apareceram mediante a relação binária, o conceito de orientalismo vai além da noção dos eixos de produção de sentido e permeia os vínculos e produções culturais.

\section{Referências}

BARTHES, R. O óbvio e o obtuso. São Paulo: Cortez, 1990.

EAGLETON, T. Ideologia: uma introdução. Traduzido por Silvana Vieira e Luís Carlos Borges. São Paulo: Ed. da UNEP, 1997.

KONDER, L. A questão da ideologia. São Paulo: Companhia das Letras, 2002.

MAIA, R. C. M. Deliberação e mídia. In: MAIA, R. C. M. (Org.). Mídia e deliberação. Rio de Janeiro: FGV, 2008

MENEGHETTI, P. D. Imagens imersivas: estudo sobre a dicotomia proximidade e afastamento no jornalismo visual. 2010. 170 f. Dissertação (Mestrado em Comunicação) - Universidade Estadual Paulista, Bauru. 2010.

PROSS, Harry. Estructura simbólica del poder. Barcelona: G. Gili, 1980.

SAID, E. W. Orientalismo: o oriente como invenção do ocidente. São Paulo: Companhia das Letras, 2007.

VEJA. São Paulo: Abril, n. 1167, jan. 1991. São Paulo: Abril, n. 1172, n. esp., 1991. . São Paulo: Abril, n. 36, out. 2003. São Paulo: Abril, n. 1795, mar. 2003.

Recebido em: 16 abr. 2013. Aceito em: 17 jul. 2013. 